\title{
Erratum: Teixidor-Batlle et al. (2020)
}

The original publication of the article Teixidor-Batlle, C., Ventura Vall-llovera, C., Reel, J. J., \& Andrés, A. (2020). Validation of a Spanish-Language Version of the Weight Pressures in Sport Scale for Male Athletes, Journal of Clinical Sport Psychology, 14(3), 221-23, https://doi.org/10.1123/jcsp.2018-0089 was incorrectly categorized as an invited paper instead of an original research paper. The online version of this article has been corrected. We apologize for this error. 